\title{
Shared Living in Israel - Higher Education as an Agent of Change in a Conflicted Society
}

\author{
Adi Binhas \\ Ph.D., Beit Berl Academic College (Kfar Saba, Israel) \\ E-mail: adibinhas@gmail.com \\ https://orcid.org/0000-0002-0791-1590
}

Binhas, Adi (2019) Shared Living in Israel - Higher Education as an Agent of Change in a Conflicted Society. Ukrainian Policymaker, Volume 5, 17-23. https://doi.org/10.29202/up/5/2

This paper focuses on academia as an agent of change in ongoing conflictual situations. In diverse and divided societies, the education system has a responsibility to promote multiculturalism in order to mitigate tension. Various theories deal with creating discourse spaces between groups in conflict: contact theory, the intergroup approach, and the narrative approach. This paper presents the role assumed by academia in Israel to bring Jews and Arabs closer together by means of two current examples - the 'Israeli Hope in Academia' project, which began two years ago under President of Israel Rivlin's tutelage, and the subsequent establishment of Centers for Shared Living on campuses as an example of execution in practice. The paper ends with practicable recommendations how the policy implementation can be improved in these centers, and can inspire other countries that experience ongoing conflicts.

Keywords: multiculturalism, conflict resolution, higher education, change agent

Received: December 2, 2019; accepted: December 11, 2019

\section{Introduction}

Israeli society is characterized by polarization and divides, both within the Jewish population that is divided into various groups and between the Jewish population and the Palestinian-Arab citizens of Israel. The State of Israel is in an ongoing battle with the Palestinians, so that Jews and Arabs are citizens of the same country, but there is a conflict between the two nation groups. Other countries face a similar reality of dealing with the routine of an unsolved conflict; for instance, the Ukraine has been in a state of conflict for a number of years, both internally and versus external forces. In the Israeli reality, the various ethnic and religious groups almost do not meet in the education system, and when they do - it is often with suspicion and tension. Various international models address the encounters and discourse between groups in conflict. This paper wishes to shed light on the actions taken by academic institutions in Israel to create

(C) Binhas, Adi, 2019 
closeness between the groups, and to present it as a national strategy aimed at mitigating tensions.

The paper opens with a theoretical review that describes multicultural education and theoretical models that deal with tension between groups, followed by a short review of strategic, structural and psychological barriers in conflicts in general, and their reflection in the Israeli-Palestinian conflict. Next, the paper focuses on the higher education system as a change agent in a conflicted heterogenous society, detailing various strategies, including defining a national goal to bring groups closer together, proclaimed by President of Israel (Reuven Rivlin) in 2017 under the title 'Israeli Hope in Academia', and the subsequent establishment of Centers for Shared Living on campuses. Finally, conclusions are drawn from the Israeli case, through which it might be able to learn how to similar develop tools in other countries. The aim of this paper is to promote thinking towards a reality in which public systems are not 'on hold', waiting for the conflict to end, but rather actively fostering moderation and closeness through (in this case, academic) institutions. Higher education as a change agent is a platform that can create bridges and links between diverse groups in an ongoing conflict.

\section{Theoretical background - Multicultural education and shared living models}

Multicultural approaches have many aspects, but in general, they aim to promote an official line that acknowledges the existence of ethnic and cultural groups, and the collective rights derived from this acknowledgement (Kymlicka, 1998). Proponents of multiculturalism see cultural diversity as an element that must be included in modern liberalism. The state must create fair policy and a range of possibilities for these groups. Multicultural policy makes room for non-dominant groups and organizes their relationships with the state through new legislation and institutions (Kymlicka \& Banting, 2006). Multicultural education includes actions that are performed in the system to respect the other, to create sensitivity to various ways of life and thought, and to move away from ethnic perceptions and stereotypes. The aim of an educational multicultural approach is to construct a varied learning environment, which provides each student from any group (whether ethnic, cultural, or social) with opportunities to sustain their diversity. The system fosters values of pluralism and encourages the individuality of the various groups, assuming that their integration enriches them, and builds up their selfconfidence versus other groups. A student need not neutralize his or her unique characteristics in order to have relationships with others (Banks \& Banks, 2010; Hsu \& Chepyator-Thomson, 2010).

To deal with situations in which diverse groups meet, approaches were formulated to cope with ensuing tensions. In certain cases, these are even groups in conflict, especially in the present era, as immigration waves are expanding, and more and more immigrants move to western countries and create new communities with different characteristics. In the Israeli case, the conflict with Arab countries and the Palestinians has been going on for decades.

The main theoretical approaches aimed at promoting shared living in a conflictual space are:

1. Contact theory: A popular model is Allport's (1954) contact hypothesis, which suggests that the best way to reduce hostility between majority and minority groups is contact between group members. Direct contact can reduce stereotypes, prejudice, and discrimination. In the nature of things, societies in conflict are rife with prejudice, and partial and erroneous knowledge about other groups. Providing 
an opportunity to get to know one another personally and directly facilitates social and personal relations with people from other groups, and consequently reduces prejudice. Encounters of this kind must insist on equal status (of the situation and context of the meeting), institutional support (laws, norms, and social atmosphere), intimate, ongoing contact that enables the development of friendships, and mutual dependence through a shared cause that requires cooperation.

2. Intergroup theory criticizes contact theory, claiming that the relationships between the groups cannot be ignored. In the Israeli case, Jewish members belong to the majority group and Israeli-Palestinians belong to the minority group, and there are gaps in the equality between the two groups (Friedberg, 2007). Minority groups typically have less access to national resources and loci of power. These elements shape the encounters and must be present in them. The encounter also serves as a basis for the reinforcement of each identity, because encounters between groups empower the investigation of each group's identity and self-definition (Maoz, 2001). Each participant represents his or her group, so that interpersonal meetings have less importance. In this context, it is the moderator's responsibility to form practices that bring the groups closer. This process often includes one-national meetings that provide a protected space that can later improve the intercultural encounter (Amir \& Ben-Ari, 1987).

3. The narrative approachis based on shared learning through the participants' narratives of their personal experiences. Telling the personal story, listening and processing it together enable discourse and joint coping with the complex political issues. The discourse does not focus on the political aspect but on the personal aspect, the participants' emotions and experiences. This approach also incorporates contact theory, because interpersonal closeness between the members is created through the narratives. The aim is also to connect each participant to his or her story as well as to expose them to the other's story (Amir \& Ben-Ari, 1987).

\section{Test case - the Israeli case - Strategic, structural, and psychological barriers in the Israeli-Palestinian conflict}

The Israeli-Palestinian conflict is an ongoing conflict characterized by complex barriers that prevent its resolution. The basis of the conflict is opposing interests regarding the basic issues such as territory and borders. However, beyond these, there are barriers rooted in differences and contradictions between identities, values, beliefs, historical narratives, collective memory, religion, myths, and ethos. The barriers that the populations must cope with, as in many other ongoing conflicts, are strategic, structural, and psychological:

1. Strategic barriers relate to the security risks of making peace, especially when either side is required to concede to territorial concessions, for example, and fear of the other side's conduct following these concessions.

2. Structural barriers are based on internal political structures that create institutional and bureaucratic constraints that make legitimization of a peace process difficult to accept. Various stakeholders such as political elites, political parties and interest groups on both sides may oppose peace processes for political, ideological and security reasons.

3. Psychological barriers include cognitive, emotional and motivational aspects, 
national narratives, and collective memories, which make it difficult to change beliefs and attitudes towards the other and the conflict. They affect the perceptions and interpretations of both sides. These barriers prevent willingness to make concessions and compromises, to take risks, or to set new priorities. Psychological barriers block fair assessment of the other, and create biases as to the other's goals and strategies as well as lack of appreciation of the other side's willingness to resolve the conflict (Bar-Siman-Tov, 2010).

\section{Analysis - Higher education as a change agent in a conflict-ridden heterogenous society}

\section{Israeli Hope in Academia}

Demographic and cultural processes have been reshaping Israeli society in recent decades: from a society composed of clear majority and minority to a society composed of four main sectors or 'tribes' close to each other in size: secular Jews, national-religious Jews, orthodox Jews, and Arabs. This situation is reflected in the numbers of first-graders in the Jewish-orthodox and Arab education systems - almost $50 \%$ of the total number of first-grade children. In this reality, there are no longer clear majority and minority answers to ideological questions, and this requires a shift from the accepted majority-minority perception to a new perception of partnership between the sectors that make up Israeli society. At the opening session of Israeli Hope in Academia, President of Israel, Reuven Rivlin, offered his vision: "Academia is the gateway to fulfilling the Israeli dream; it is the entry ticket for all of us to loci of influence. It is the first that creates a space that can serve to form a common language and goals, in which a sense of belonging and responsibility can be forged. Academia can and should be a lighthouse for the understanding that human variety and diversity are not a threat — but an advantage. The road to Israeli hope leads through the willingness and effort to integrate and diversify" (Hendin \& Alon, 2017).

This project, initiated in 2017, includes about thirty academic institutions, and is intended to establish the partnership between the various parts of Israeli society in several arenas, primarily academia, employment, education, sport, and local government. All these arenas become change agents of shared and uniting ideas. In the context of this paper, Israeli Hope in Academia operates to promote a varied, culturally-fit environment, which prepares its graduates for shared living and commitment to integrate in the work market. Israeli Hope in employment fosters diversity, representation and cultural fitness, with emphasis on integrating Arabs and orthodox Jews in industry. Israeli Hope in education promotes education for partnership, given the four separate education systems. Israeli Hope in sport works to foster tolerance and coping with violence and racism. Academia is indeed one actor, but the others are linked to it and derived from it (for instance, employment integration and education). The activity in the various arenas is characterized by creating extensive cooperation with government offices, foundations and civil society organizations. The President's residence serves as an organizing factor of these partnerships, and as an engine that can bring all the partners to the table to lead the desired change, in an attempt to form a new moral, value-oriented standard in light of the changes that Israeli society is experiencing.

The academic context of shared living - in practice

At the outset of a discussion about implementing 'shared living in academia', we should first define 'shared living'. The concept consists of knowing the other, the different, through dialog 
and respect for cultural diversity and the other, and through recognition of the importance of shared civil commitment. This perception is congruent with the definition of partnership in the Israeli Hope project: "Equality between the partners, mutual respect and legitimization, recognition of each side's national and cultural existence, positive and fair relationships through empathic and sensitive dialog, a sense of shared responsibility, and shared striving for peace" (Issawi Report, 2009).

Decision-makers in the higher education system realized academia's significant role in bringing populations closer together before the President's 2017 project. In the reality of life in Israel, academic institutions are often the first place that Jews and Arabs meet. The academic framework can be used not just to impart academic knowledge, but also to create discourse between the groups, to reduce prejudices, and to generate social and cultural closeness. Higher education institutions have operated for years to promote these causes. The more relevant institutions are teacher-training colleges, which train the educators of the future generation of Israeli citizens. The aspiration of teacher-training colleges is to mold the social change agents (teachers) through own values of equality and intercultural dialog can be fostered. The colleges view these values as their mission; encourage multicultural and multi-identity education, social solidarity, equality, and justice. There are 29 teacher-training colleges in Israel, including teacher-training programs in public universities. Although about half of these programs declare concrete tasks in the abovementioned areas, only few relate in practice to the concepts of multiculturalism, conflict resolution, or shared learning.

A document written by an Arab researcher and a Jewish researcher (Jayusi \& ZalmansonLevi, 2018) entitled 'Multiculturalism and shared living between Jews and Arabs in academic teacher-training colleges' presents information on encounters between Jews and Arabs in education departments and university-based teacher-training programs. According to the Council for Higher Education (2018), the rates of Arab students in humanities and education departments in 2018 were $20 \%$ in teacher-training colleges (and they are $24 \%$ of all college students), and $22 \%$ in universities; i.e., about one of every five students is an Arab. The report discusses the shared space between Jews and Arabs in teacher-training institutions, and describes the majority-minority relations in academia, the recent developments and actions taken, and what should be done in the future. In order to expand and improve the familiarity between the groups, various forums at academic institutions in collaboration with civil society organizations contribute in varied ways including focused workgroups of staff members, joint student activities, and attempts to form awareness of the issue in academic institutions (Lautman Forum for Educational Policy, 2017). The various institutions have different student bodies and varied policies, but the meetings between them create a shared language on the issue of 'shared living'. At this author's college, which is also a teacher-training college, the Center for Shared Living is headed by Dr.WurudJayusi. The center conducts various activities designed to bring Arabs and Jews closer together through learning languages, cultural events, joint conferences, etc. When Jews and Arabs are exposed to each other's stories and get to know each other in person, mutual stereotypes fade away. The problems between the groups are also discussed at these meetings. The intention is not to 'run away' from problem topics or discussion of the conflict. There is joint activity, shared learning, and an understanding that there are uniting elements between the groups, and that they should be given space to be expressed and developed (author's personal experience). 


\section{Conclusions and recommendations}

The Israeli case, in which academia assumed the role of change agent and initiated activities to bring diverse groups closer, shows that closeness can be created, even in public institutions, and even when there is an ongoing conflict. In citizens' everyday life, encounters transpire in various arenas - academia, employment, society and culture. If mutual familiarity and closeness occur, the conflict that is constantly in the background can be felt less in everyday life. Academia is in fact a meeting place in which majority-minority power relations exist, but academia (by definition) also facilitates discourse, pluralism, and opportunities for encounters and reciprocity between diverse groups. The research report written in Israel (Jayusi \& Zalmanson-Levi, 2018) proposed operative recommendations to improve the goals of shared living in academia. These recommendations can be relevant to other countries (such as the Ukraine) where there is an ongoing conflict. The recommendations were grouped into three areas:

Pedagogy - It was suggested to conduct courses that deal with the conflict and its various aspects, and that these courses teach Jewish and Arab students together. It can be seen that the contact theory, the intergroup theory and the narrative approach are reflected in this recommendation. Students study together, and hear each other's historic narrative. Also, these courses should have more or less even numbers of Jewish and Arab students.

Language and culture- The Arabic language is not spoken by most Jews. The report proposed to expose groups of Jewish students to the Arabic language and culture. Some colleges conduct Arabic courses for Jewish students and other events for both populations in the context of language and culture.

Institutional - The willingness of the academic establishment to promote the topic of 'shared living' is necessary. A review of academic institutions revealed that 16 of them operate centers for shared living (at the author's college, the center is headed by one of the authors of the report, Dr.WurudJayusi). It is recommended that the center is led by two managers Jewish and Arab. The centers operate the activities on campus, raise the students' and staff's awareness of the possible experiences, and deal with fundraising and pooling of resources.

\section{미] References}

Allport, Gordon W. (1954). The Nature of Prejudice. Reading, Mass: Addison-Wesley.

Amir, Yehuda, and Rachel Ben-Ari (1987). Encounters between Jewish and Arab youth in Israel — reality and potential. Megamot, 30(3), 305-315. (Hebrew)

Banks, James A., and Cherry A. McGee Banks. (Eds.) (2010). Multicultural education: Issues and perspectives. John Wiley \& Sons.

Bar-Siman-Tov, Yaakov (2010). Barriers on the road to conflict resolution. In Y. Bar-SimanTov (Ed.), Barriers to peace in the Israeli-Palestinian conflict (pp. 15-27). Jerusalem Institute for Research of Israel. (Hebrew)

Council for Higher Education (2018). Increase in the number of students from the Arab sector. Jerusalem: n/p. (Hebrew)

Friedberg, Daniel (2007). Between the personal and political: Theory of practice in leading dialog group encounters of Jews and Palestinians in Israel. Master's thesis. Hebrew University, Jerusalem. (Hebrew)

Hendin, Ayala (2017). Israeli Hope in Academia. Jerusalem: Presidential residence. (Hebrew) 
Hsu, Shan-Hui, and Rose Chepyator-Thomson (2010). Multiculturalism in secondary school physical education textbooks. Journal of Teaching in Physical Education, 29(2), 199220. https://doi.org/10.1123/jtpe.29.2.199

Issawi Report (2009). Report of public committee to formulate the official policy on education for shared living between Jews and Arabs. http://commonground.cet.ac.il/ShowItem. aspx (Hebrew)

Jayusi, Wurud, and Galia Zalmanson-Levi (2018). Multiculturalism and shared living between Jews and Arabs in academic teacher-training colleges. Position paper. The Association for Civil Rights in Israel. (Hebrew)

Kymlicka, Will (1998). Finding Our Way: Rethinking Ethnocultural Relations in Canada. Oxford: Oxford University Press.

Kymlicka, Will, and Keith Banting (2006). Immigration, Multiculturalism and the Welfare State. Ethics and International Affairs, 20(3), 281-304. https://doi.org/10.1111/j.17477093.2006.00027.x

Lautman Forum of Educational Policy (2017). Shared living coordinators within the informal education system. http://lautmaneduforum.org.il/wp-content/uploads/2017/09/life.pdf (Hebrew)

Maoz, Y. (2001). Conceptual mapping and assessment of Jewish-Arab coexistence activities in Israel: Summary report. Jerusalem: Keren Avraham. (Hebrew) 